\title{
Public Access Management as an Adaptive Wildlife Management Tool
}

By Douglas S. Ouren and Raymond D. Watts

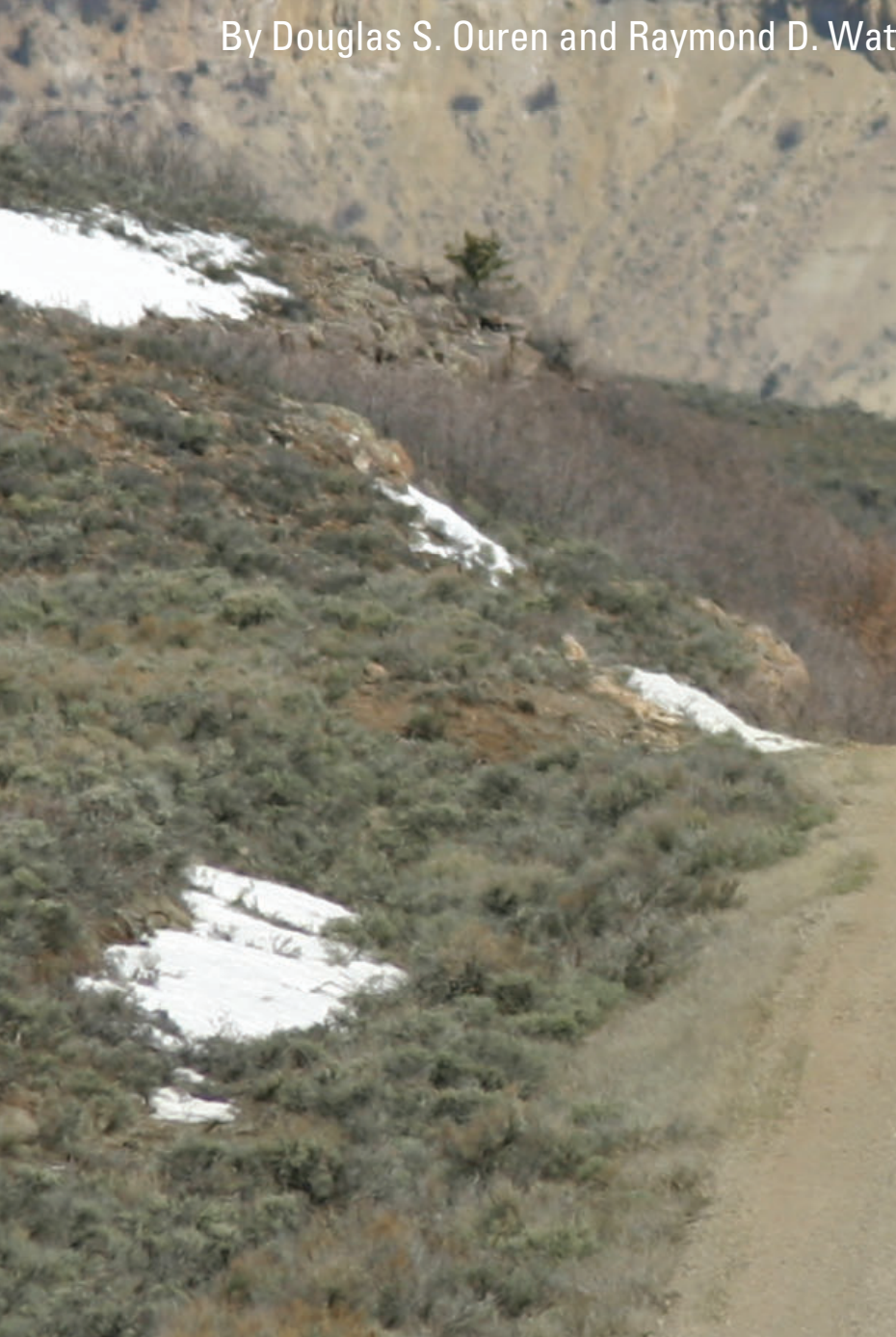

Open-File Report 2005-1349

U.S. Department of the Interior

U.S. Geological Survey 


\section{U.S. Department of the Interior \\ Gale A. Norton, Secretary}

\section{U.S. Geological Survey \\ P. Patrick Leahy, Acting Director}

U.S. Geological Survey, Reston, Virginia 2005

For product and ordering information:

World Wide Web: http://www.usgs.gov/pubprod

Telephone: 1-888-ASK-USGS

For more information on the USGS - the Federal source for science about the Earth, its natural and living resources, natural hazards, and the environment:

World Wide Web: http://www.usgs.gov

Telephone: 1-888-ASK-USGS

Suggested citation:

Ouren, D.S., and Watts, R.D., 2005, Public access management as an adaptive wildlife management tool: U.S. Geological Survey, Biological Resources Discipline, Open-File Report 2005-1349, 10 p.

Any use of trade, product, or firm names is for descriptive purposes only and does not imply endorsement by the U.S. Government.

Although this report is in the public domain, permission must be secured from the individual copyright owners to reproduce any copyrighted material contained within this report. 


\section{Contents}

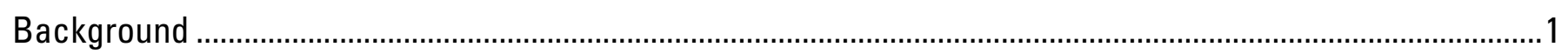

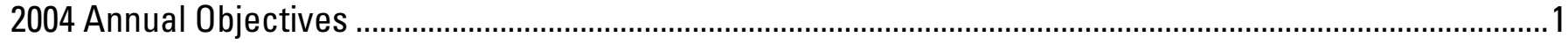

Meetings with Collaborators and Partners.........................................................................................

Selection and Deployment of Vehicle Counters ………………………………………….......................

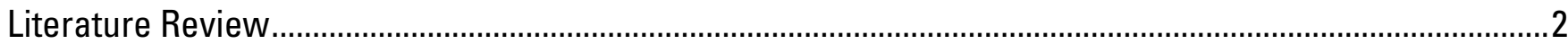

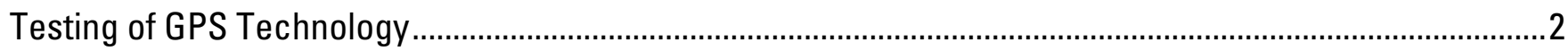

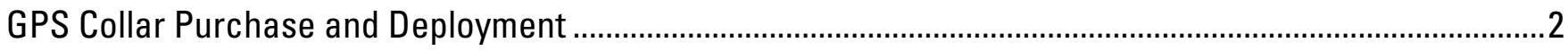

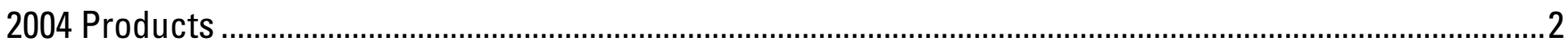

Goals and Objectives for FY2005 ................................................................................................................

Appendix I. Available Motorized Vehicle Monitoring Technologies.............................................................. 10 


\section{Public Access Management as an Adaptive Wildlife Management Tool}

\section{Preliminary Report}

Primary Contact and Principal Investigator

Douglas S. Ouren, USGS Fort Collins Science Center; 2150 Centre Ave. Bldg. C, Fort Collins, Colorado 80526-

8118. E-mail doug_ouren@usgs.gov. Phone 970-226-9476.

\section{Co-Investigator}

Raymond D. Watts, Rocky Mountain Mapping Center and Fort Collins Science Center, 2150 Centre Ave. Bldg. C, Fort Collins, Colorado 80526-8118. E-mail rwatts@usgs.gov, Phone 970-226-9378.

\section{Background}

Wildlife populations across the United States are benefiting from improved wildlife management techniques. However, these benefits also create new challenges including overpopulation, disease, increased winter kill, and forage degradation. These issues have become the challenges for natural resource managers and landowners. Specifically, elk (Cervus elaphus) populations in the Gunnison River Valley of Colorado are growing and causing increased resource damage on public and private lands. On public lands elk threaten sage grouse habitat and compete with domestic livestock for available forage; on private lands they diminish available livestock forage. Management of elk and elk habitat in this area is a shared responsibility of the NPS (Black Canyon of the Gunnison National Park and Curecanti National Recreation Area), BLM (Uncompahgre Field Office), USFS (Gunnison National Forest), and the CDOW (Colorado Division of Wildlife). All of these agencies participate in this research and adaptive management project.

One key issue in the Black Mesa - Black Canyon area is the interaction between motorized vehicles and. The working hypothesis for this study is that early season elk movement onto private lands and the National Park is precipitated by increased use of Off Highway Vehicles (OHV's). Data on intensity of motorized use is extremely limited. In this study, we monitor intensity of motorized vehicle and trail use on elk movements and habitat usage and analyze interactions. If management agencies decide to alter accessibility, we will monitor wildlife responses to changes in the human-use regime. This provides a unique opportunity for adaptive management experimentation based on coordinated research and monitoring. The products from this project will provide natural resource managers across the nation with tools and information to better meet these resource challenges.

\section{Annual Objectives}

The goals for 2004 were to:

- develop funding for the full scope of the study,

- work with management agencies to develop a collaborative foundation for research and applications,

- $\quad$ initiate traffic monitoring field work,

- $\quad$ initiate testing of GPS (Global Positioning System) technology for animal tracking in 2005.

\section{Meetings with Collaborators and Partners}

Our initial meeting with collaborators occurred $18 \mathrm{Feb}, 2004$. At this meeting we gave a presentation on past and present work. Past work has been on investigation of the impacts of the physical presence of roads and motorized traffic on wildlife habitat selection, specializing on instrumental observation of motorized traffic on roads and trails and continuous GPS monitoring of animal movements. We showed a video of grizzly bear movements in the Yellowstone area that illustrated highly variable patterns of movement that would be nearly impossible to properly interpret from VHF (very high frequency) collar location data.

All collaborators were present at a progress meeting on 4 Aug. 2004, where we made a presentation to the Habitat Partnership Program, a collection of land owners and federal land managers and the Colorado Division of Wildlife in the area.

\section{Selection and Deployment of Vehicle Counters}

Monitoring motorized vehicle use can be done using a number of different technologies including inductive, magnetic, seismic, pneumatic, and infrared methods. We have done significant testing with each of these technologies and have found that they all have their advantages and disadvantages which are discussed in Appendix 
1. For this project we will be using pneumatic counters on the maintained roads and magnetic counters for the majority of the off highway vehicle routes.

In June 2004 the U.S.F.S. Paonia District of the Gunnison National Forest and the NPS Black Canyon National Park purchased pneumatic vehicle monitoring equipment for this project. A total of seven counters were purchased for the initial deployment.

On 19 July 2004 we deployed four vehicle counters to develop baseline values for motorized use in the study area. These pneumatic counters provided data on time, date, vehicle type, speed and direction of travel. On 11 October we installed three additional counters and downloaded data from the first four. Of these four, one pneumatic tube with an apparent puncture needed replacement; another had lost some of its anchors. We reanchored this and other pneumatic tubes, thus improving our field installation methods.

All counters were removed from the field on 12 December. A preliminary traffic analysis is included in this report (see pages _ _). In the upcoming field season we will redeploy the pneumatic counters and will complement these with infrared (IR) and magnetic sensors. The IR and magnetic counters will be used primarily in areas where OHV's make up the majority of the use.

\section{Literature Review}

We are completing a literature review of the impacts of roads on wildlife habitat selection and use. The current bibliography has over 3000 citations, with the earliest citations being from 1905 . Much of the literature deals with physical effects of roads ranging from erosion and sediment control to air quality problems; less than one percent of the articles address the impacts of the motorized use of roads on wildlife.

\section{Testing of GPS Technology}

For the past six months we have been testing the GPS/VHF technology that we will deploy for elk movement studies. There are a number of GPS collars available that provide data collection 24 hours a day each day of the year with a location precision less than 30 meters. The collars scheduled provide data downloads using a VHF receiver. Earlier collars either required physical recovery for download or were unreliable for download by radio link. The new collars have proven to transmit data that can be accurately downloaded at ranges up to $10 \mathrm{~km}$. This advance in technology provides detailed records of movement on a regular schedule, without waiting for collar release and without additional animal handling.

\section{GPS Collar Purchase and Deployment}

Currently the CDOW plans to provide eighteen GPS/VHF elk collars. CDOW is optimistic that there will be funds available to purchase additional collars in the upcoming year. The Grand Mesa, Uncompahgre and Gunnison National Forests, with input from the CDOW and the USGS, have submitted a proposal to the Rocky Mountain Elk Foundation for funding for additional collars. Resource management personnel of the Black Canyon of the Gunnison National Park and Curecanti National Recreation Area submitted a NPS proposal to provide additional equipment and operational funding for elk monitoring. Unfortunately, their proposal narrowly missed the FY 2006 allocation, but the plan is to refine the proposal and resubmit it for FY 2007.

The elk tracking plan is to deploy collars as they become available, capturing animals in locations at times that give greatest likelihood that the individuals are part of problematic populations. As is customary with elk movement studies, mature cows will be preferred collar bearers.

\section{Products}

- Motorized vehicle monitoring results (551 counter days)

- Study area maps

- Project and funding proposals

\section{Goals and Objectives for FY2005}

- continue Motorized Vehicle monitoring

- use magnetic counters to monitor OHV use

- deploy GPS/VHF collars on elk

- conduct project update meetings

- work on obtaining operational funding from all partners 


\begin{tabular}{|lrr|}
\hline \multicolumn{3}{|c|}{ Corral Gulch Road } \\
\hline Location (UTM Zone 13 NAD83) & $283082.52 \mathrm{E}$ & $4262631.51 \mathrm{~N}$ \\
Survey Duration & $8 / 19 / 2004$ & $12 / 12 / 2004$ \\
Period of record (in days) & 115 & \\
Total vehicle counts & 3478 & \\
Average speed & $40.70 \mathrm{mph}$ \\
\hline
\end{tabular}

This site is located on Corral Gulch road (FS RD \# 719) approximately 1.5 miles from Highway 92 and just before FS RD \# 2A on USFS lands. This road is currently being used to access an ongoing logging operation but is also used as access to private in holdings and recreational pursuits. The Coral Gulch road also provides access to FS RD\# 713, 716 and 717 all which provide access to the Black Mesa area.
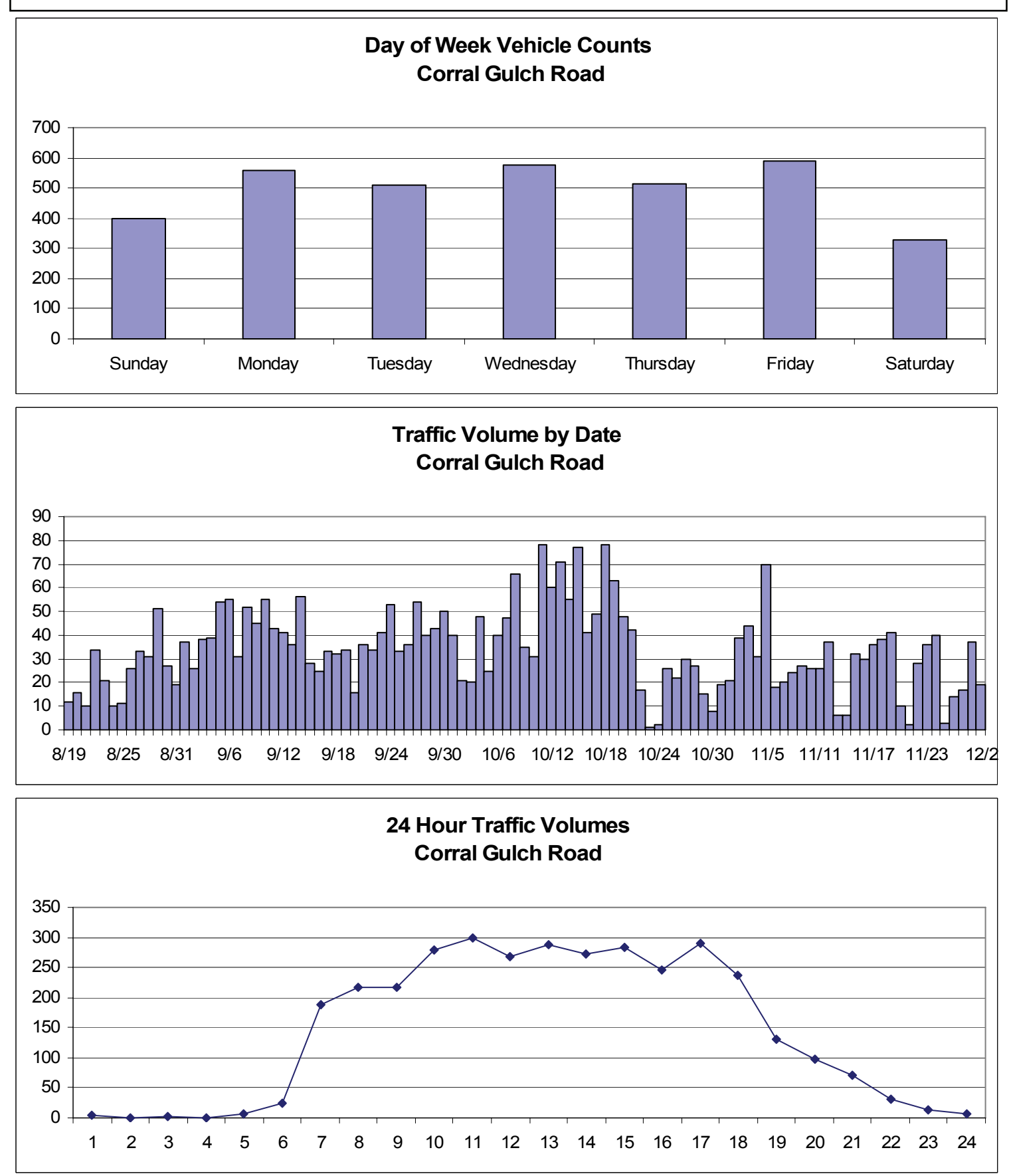


\begin{tabular}{|lrr|}
\hline \multicolumn{3}{|c|}{ Gould Reservoir Road } \\
\hline Location (UTM Zone 13 NAD83) & $275365.47 \mathrm{E}$ & $4275202.01 \mathrm{~N}$ \\
Survey Duration & $8 / 20 / 2004$ & $11 / 30 / 2004$ \\
Period of record (in days) & 102 & \\
Total vehicle counts & 414 & \\
Average speed & $22.8 \mathrm{mph}$ \\
\hline
\end{tabular}

Site is on Montrose Cnty RD E 81 and provides access to private lands and to the Poison Spring Ridge area whose federal lands are managed by the BLM. The majority of use in this area is recreational.
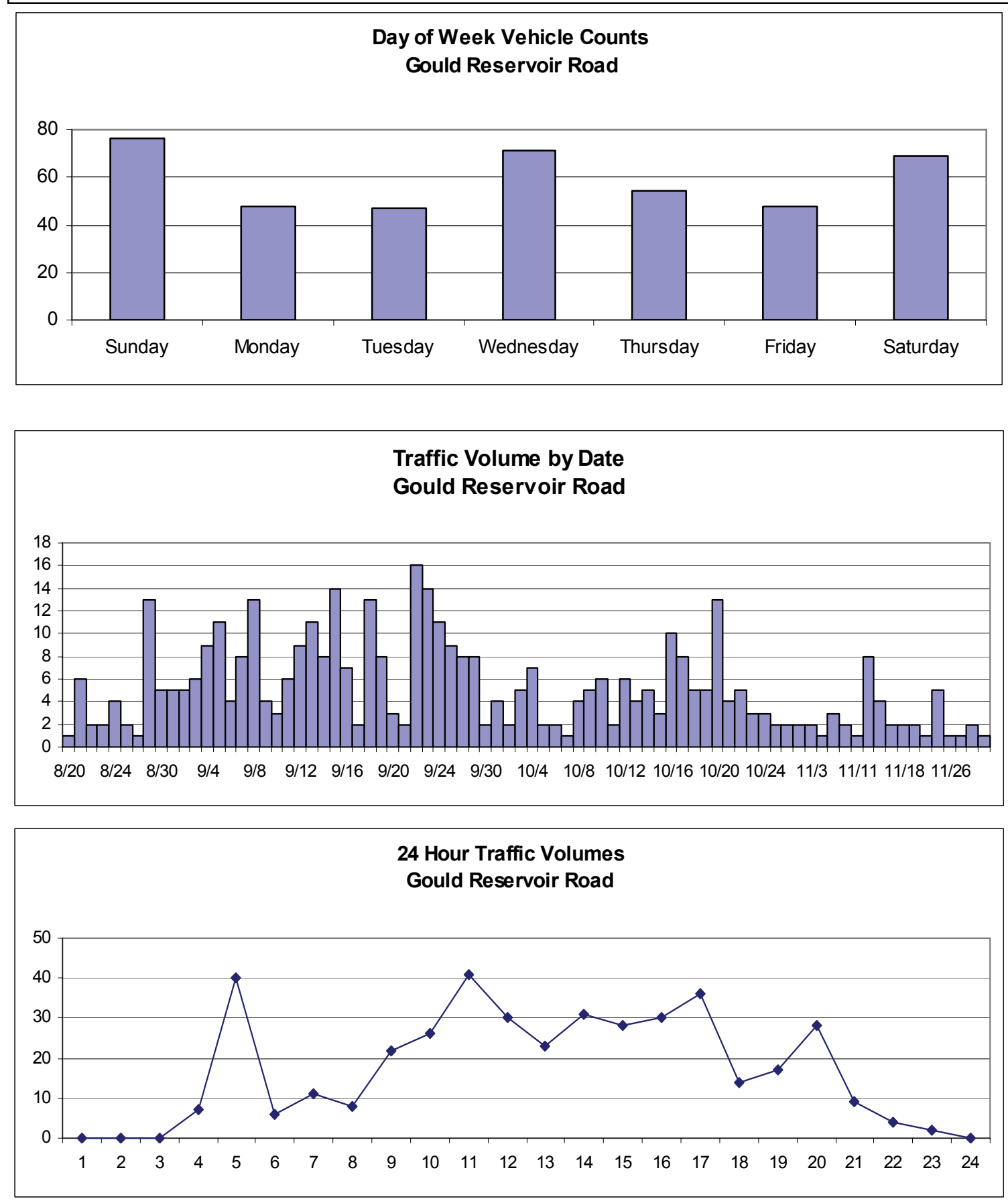


\begin{tabular}{|lrr|}
\hline \multicolumn{3}{|c|}{ Grade Road } \\
\hline Location (UTM Zone 13 NAD83) & $280331.41 \mathrm{E}$ & $4270075.81 \mathrm{~N}$ \\
Survey Duration & $8 / 19 / 2004$ & $11 / 26 / 2004$ \\
Period of record (in days) & 99 & \\
Total vehicle counts & 3685 & \\
Average speed & $30.0 \mathrm{mph}$ & \\
\hline
\end{tabular}

Site is on the main the Old Grade Rd(FS RD \# 716) just beyond the intersection with the Crystal Creek Roads. This route provides motorized vehicle access to the Black Mesa area, including USFS motorized vehicle routes FS RD \# 717 and \# 715) and is used mainly for recreation. This road can also provide access to the Corral Gulch road (FS RD \# 719). During this monitoring period there was logging activity in the Corral Gulch area.
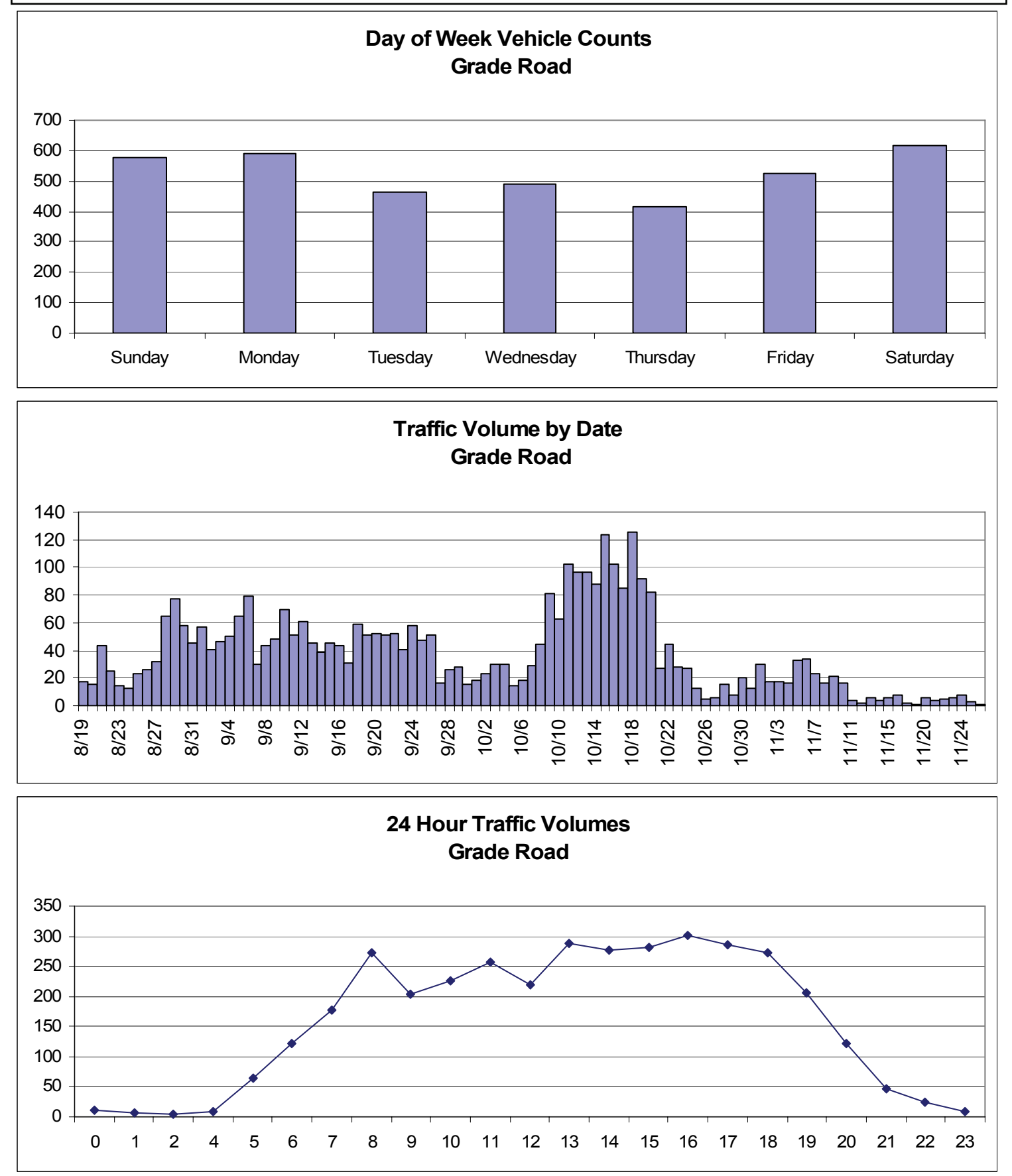


\begin{tabular}{|lrr|}
\hline \multicolumn{4}{c|}{ Pine Ridge Road } \\
\hline Location (UTM Zone 13 NAD83) & $276295.42 \mathrm{E}$ & $4267173.02 \mathrm{~N}$ \\
Survey Duration & $8 / 19 / 2004$ & $11 / 18 / 2004$ \\
Period of record (in days) & 91 & \\
Total vehicle counts & 137 & \\
Average speed & $13 \mathrm{mph}$ \\
\hline
\end{tabular}

The Pine Ridge road site is on an unnumbered USFS road just west of highway 92 . The counter is located approximately .75 miles up the Pine Ridge road from the highway. This road provides access to private property as well as to hunting on USFS lands.
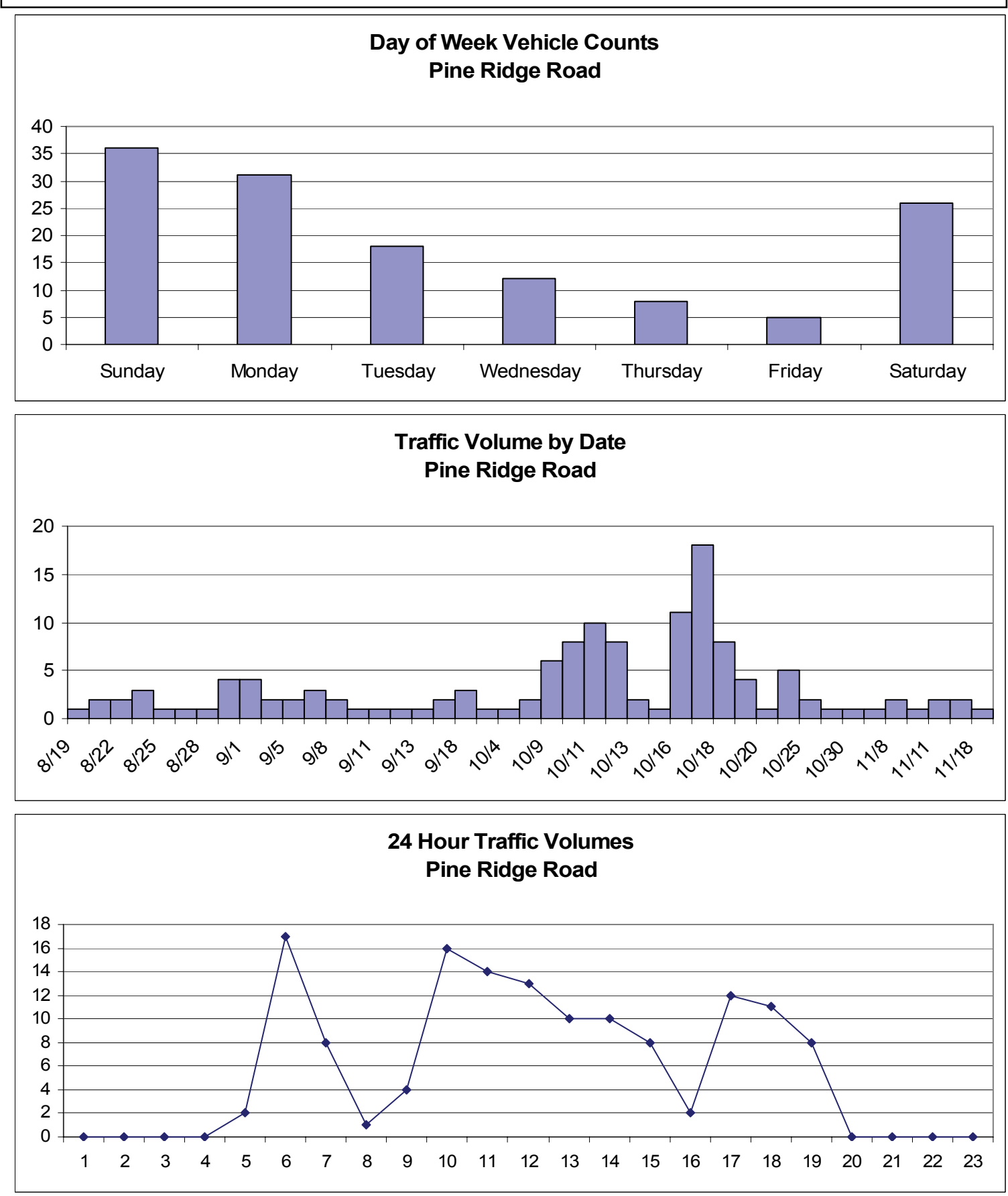


\begin{tabular}{|c|c|}
\hline \multicolumn{2}{|c|}{ Crystal Creek Main Road } \\
\hline Location (UTM Zone 13 NAD83) & $280305 \mathrm{E}$ \\
\hline $\begin{array}{l}\text { Survey Duration } \\
\text { Period of record (in days) } \\
\text { Total vehicle counts }\end{array}$ & $\begin{array}{l}8 / 19 / 2004 \quad 12 / 7 / 2004 \\
93 \text { days (less } 19 \text { days due to } \\
\text { equipment failure) } \\
4189\end{array}$ \\
\hline Average speed & $42.3 \mathrm{mph}$ \\
\hline
\end{tabular}

Site is on the main road into the Crystal, Montrose Cnty Rd J82(FS road \# 713)and Dyer Creek drainages. Counter was located at the Forest Service sign just beyond the junction of the Old Grade $\operatorname{Rd}(\mathrm{FS}$ road \# 716) and the Crystal Creek Roads. This route provides motorized vehicle access to the Dyer creek drainage, including USFS motorized vehicle routes FS RD \# 717 and \# 715 and is used mainly for recreation. pursuits. This road can also provide access to the Corral Gulch road (FS RD \# 719). During this monitoring period there was a logging activity in the Corral Gulch area.
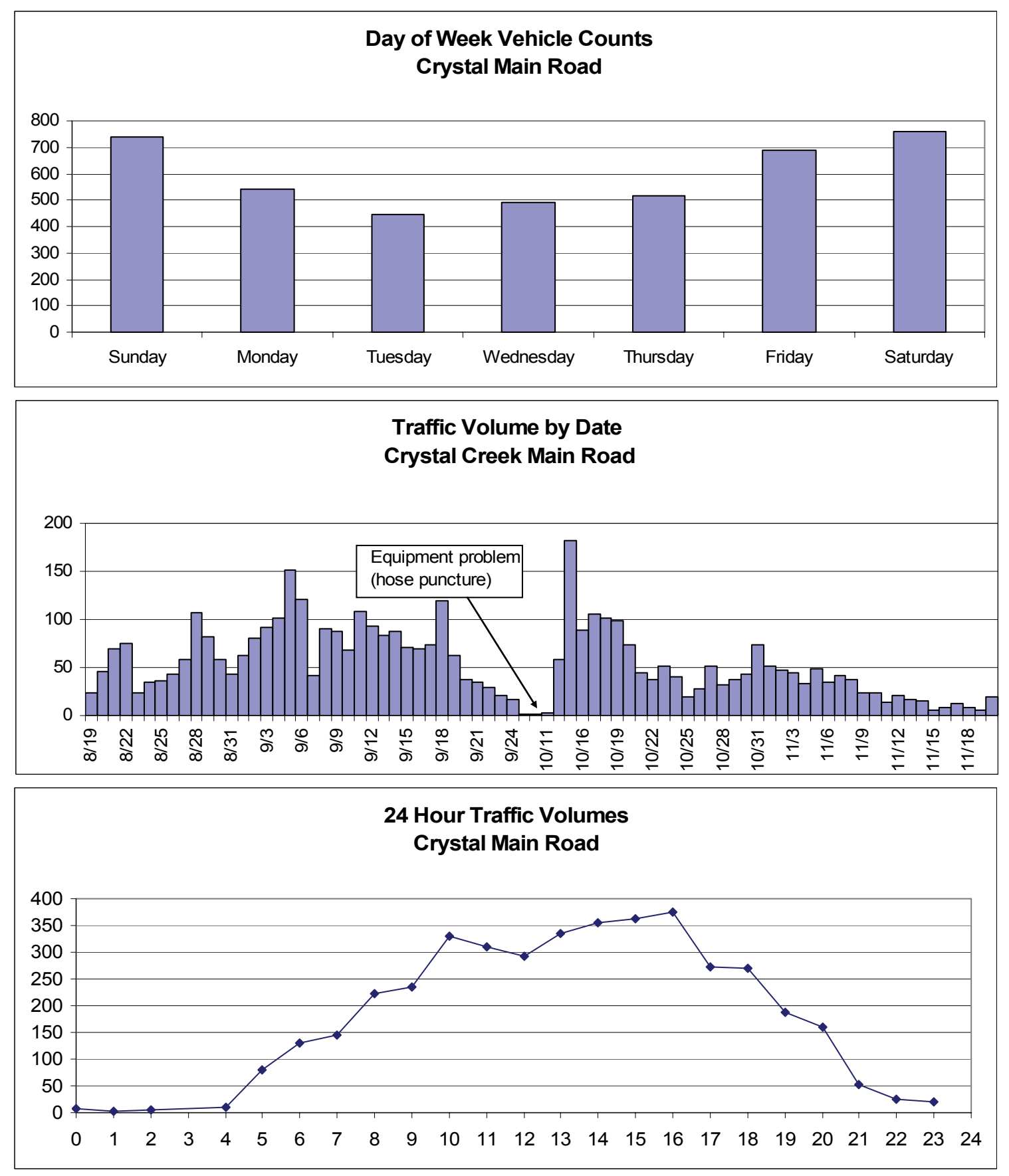


\begin{tabular}{|lrr|}
\hline \multicolumn{3}{|c|}{ Lek Road } \\
\hline Location (UTM Zone 13 NAD83) & $269376.19 \mathrm{E}$ & $4279339.90 \mathrm{~N}$ \\
Survey Duration & $10 / 15 / 2004$ & $11 / 27 / 2004$ \\
Period of record (in days) & 43 & \\
Total vehicle counts & 965 & \\
Average speed & $24.1 \mathrm{mph}$ \\
\hline
\end{tabular}

The Lek road counter is located on Montrose Cnty RD C77. This is the major motorized access route providing access by the BLM and the NPS lands, including the Parvin Gulch area and Red Canyon. This road has seasonal closure because of the nearby Gunnison Sage Grouse lek sites.
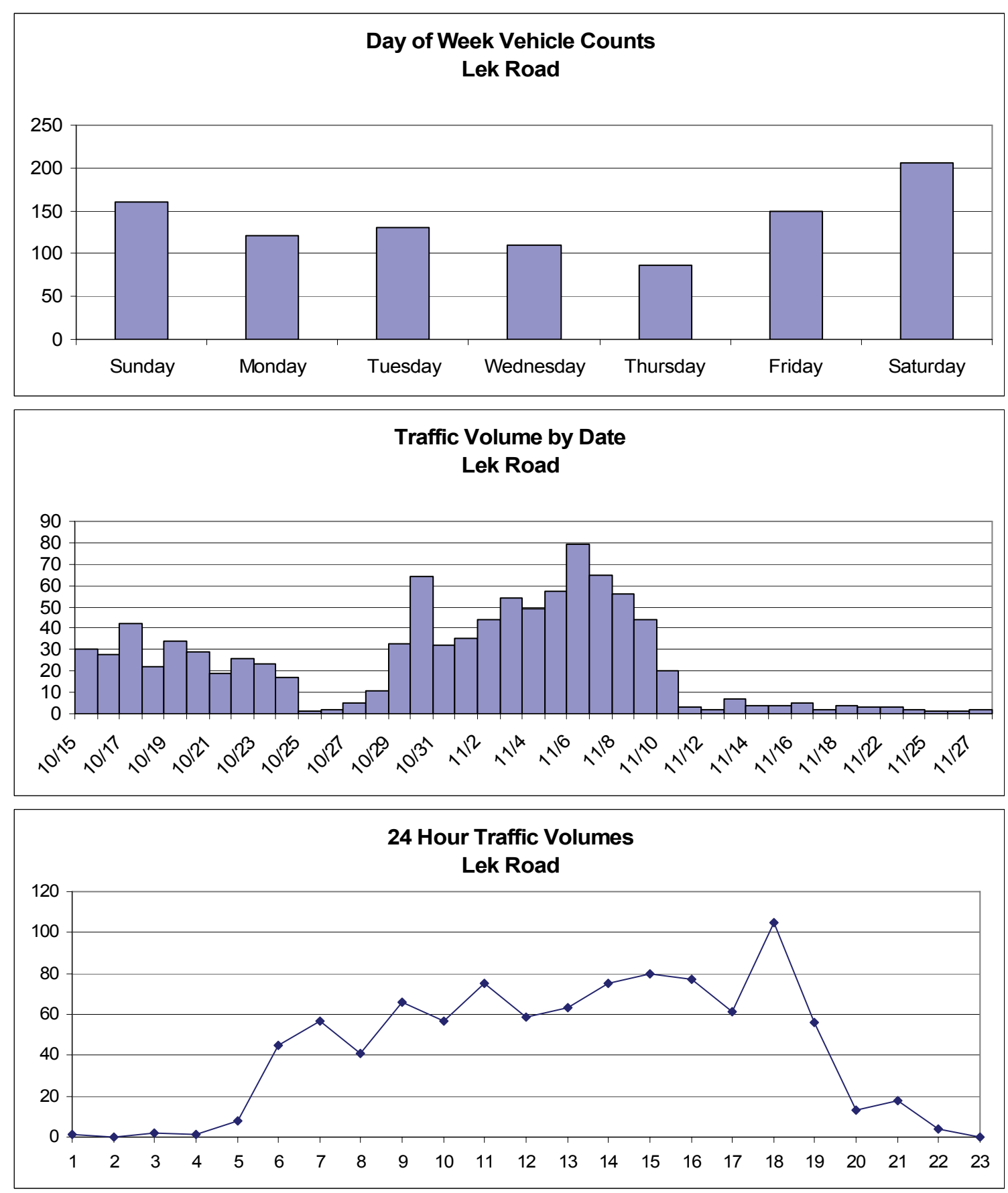


\begin{tabular}{|lrr|}
\hline \multicolumn{3}{|c|}{ Poison Springs Road } \\
\hline Location (UTM Zone 13 NAD83) & $269842.37 \mathrm{E}$ & $4278837.31 \mathrm{~N}$ \\
Survey Duration & $10 / 14 / 2004$ & $11 / 1 / 2004$ \\
Period of record & 18 days & \\
Total vehicle counts & 795 & \\
Average speed & $45.9 \mathrm{mph}$ & \\
\hline
\end{tabular}

The Poison Springs vehicle counter is located on Montrose Cnty RD D77 within BLM lands. This road provides motorized vehicle access to the Poison Springs Ranch and other private properties in the area as well as BLM lands on Fruitland Mesa.
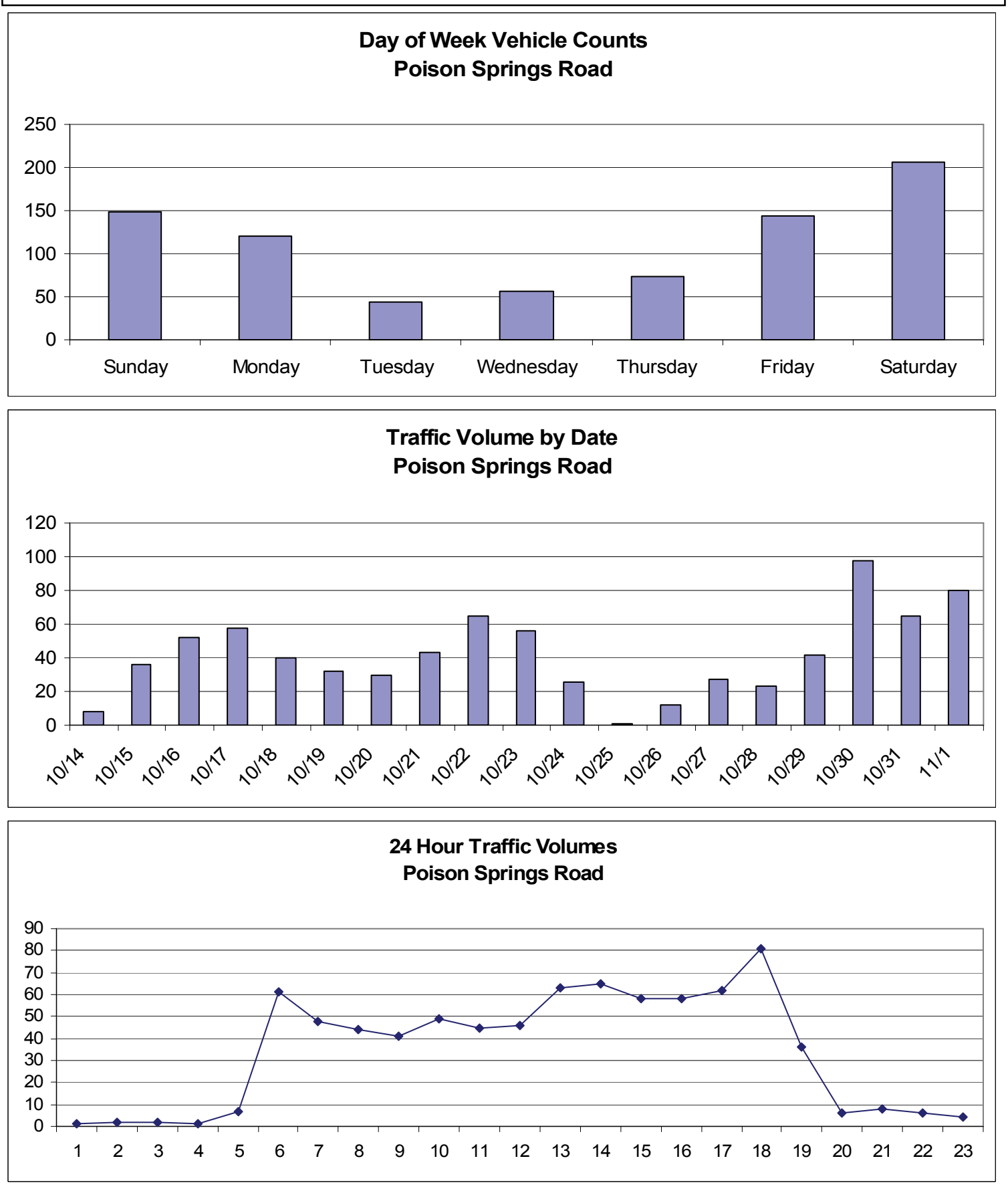


\section{Appendix I. Available Motorized Vehicle Monitoring Technologies}

Technology is advancing rapidly to help wildlife scientists and managers answer questions about the intensity of motorized vehicle use. There are six major technologies for counting vehicles:

1. Inductive loop. A wire loop is buried in the roadway, through which an alternating current is passed. The presence of an electrical conductor (vehicle) over the loop changes the voltage-current relationship (inductive reactance), and an instrument senses the presence of the conductor. This technology is frequently employed to trigger traffic signals. Installation is a complex field operation, and the system requires careful tuning to the proper sensitivity. This technology cannot count nonmetallic objects, such as skiers and hikers.

2. Pressure sensor. The most common device is the pneumatic tube sensor. One tube system counts axle crossings, with no discrimination of speed, travel direction, or vehicle type. Two-tube pneumatic systems add these significant parameters. Instrument packages are robust and operate for many months on one battery pack. Disadvantages are easy visibility and possible vandalism, vulnerability to snowplowing and other mechanical operations, and missed counts in snow or muddy conditions. Pneumatic systems count neither snowmobiles - because they have a low-pressure footprint — nor humans on foot or ski.

3. Magnetic. There are several types of magnetometers capable of sensing nearby magnetic objects. Automobiles and trucks are sufficiently magnetic to be detected, but snowmobiles with aluminum engine blocks may not be. This is an area of current investigation. Advantages are insensitivity to environmental conditions and invisibility (the instrument package can be buried in or alongside the road). Disadvantages are inability to count nonmagnetic objects and sensitivity to small changes in the earth's magnetic field.

4. Seismic. These instruments sense shaking caused by vehicle passage. They are most effective when installed on bridges or other weight-bearing structures, and otherwise must be very close to the passing vehicle. Instruments are expensive and installation difficult. Seismic systems do not sense lightweight or slow traffic.

5. Photographic. Older film systems had significant mechanical and power limitations. Newer digital camera systems also have power and memory limitations. It is possible, however, to couple these systems with triggering sensors (the other five listed here) and provide unambiguous identification of the cause of the triggering counter.

6. Infrared. These are passive sensors that detect radiant temperature changes. They contain small optical components that measure average temperature over a certain field of view. Infrared counters sense vehicles, animals, and people - a wide range of observations. This wide range can, however, be a disadvantage; there is no direct way, short of pairing the counter with a camera, to identify the cause of an event.

For the present study, we will be using a combination of pneumatic, infrared and magnetic monitoring equipment. 